\title{
Which operation is described?
}
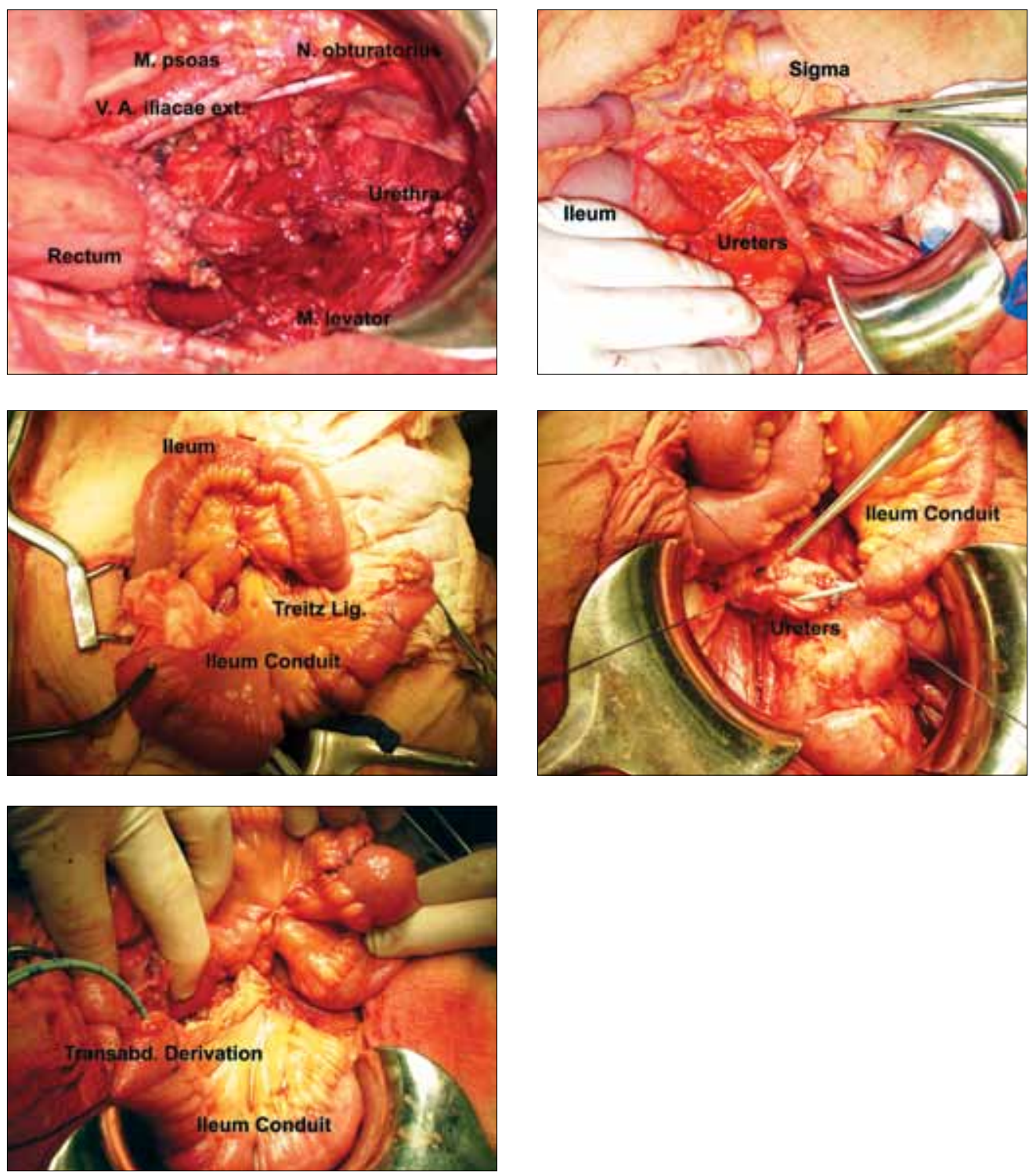

Address for Correspondence: Assoc. Prof. Cemil Yaman, Krankenhausstr. 94020 Linz, Austria 


\section{Bricker conduit during Type I supralevatoric anterior evisceration for relapsed cervical carcinoma"}

Local recurrence of cervical cancer after radiation therapy is probably one of the most complications. Up to $70 \%$ of patients with cervical cancer receive radiation at some point in their treatment. It is well known that one out of three of these patients will suffer recurrent or persistent disease. In more than $80 \%$ of these cases, the disease will recur within the first 2 years after treatment (1).

Recurrent local disease after radiation therapy cannot be easily treated. Chemotherapy has been used in this situation with very poor results. Typically, the effectiveness of chemotherapy is very low after radiation failure, and chemotherapy is used only with palliative intent (2).

Re-irradiation may be proposed in very highly selected cases after a long interval free of disease. However, re-irradiation dramatically increases the rate of severe complications, especially fistulas, if used shortly after the first treatment Only a pelvic exenteration or evisceration can achieve tumor-free margins in these cases. During the last 60 years, this surgery has been proven successful in selected cases of recurrent pelvic cervical cancer after radiation, obtaining 5 -year overall survival rates higher than $30 \%(3,4)$.

In 1948, Brunschwig was the first surgeon to publish his preliminary experiencewith pelvic exenteration. Soon, his technique started to be used in other American institutions, becoming the gold standard of treatment in recurrent cervical cancer after radiation (5-7).

However, urinery diversion can be needed after bladder resection. The goal of any form of urinary diversion is to deliver the urine to outside with a minimum interference of life style, with a maximum protection of the urinary tract. Since Bricker first described his procedure in 1950, the ileal conduit has been the gold standard for urinary diversions after cystectomy for bladder cancer or after exenteration for a gynecological relapse in irradiated patients (Fig. 1, 2). A 15-to 20-cm-long distal ileal segment is isolated (Fig. 3), and the ureters are implanted in the proximal end (Fig. 4 and 5) or in the antimesenteric edge.The stoma is usually below and to the right of the umbilicus (8).

Most gynecologic oncologists who perform exenteration use this maneuver. With Magrina's classification, exenteration is divided into supralevator (type I), infralevator (type II) and infralevator with vulvectomy (type III), and, an additional category, extended (7). This division can help to facilitate communication when referring to these patients. It can also facilitate a more detailed analysis of operative risk factors, complications, and results and can increase our knowledge of the indications and limitations of the different exenterative procedures. In the gynecologic oncology setting, a colostomy is also widely used, but there are a number of reasons to choose an ileostomy as the preferred temporary stoma in these patients: 1 . Ileostomy not only protects the colorectal anastomosis but also may protect the small bowel anastomosis that closes the donor area for the urinary conduit. 2. Commencement of small bowel function is almost immediate, allowing patients to eat sooner. 3 . The rate of complications in the small bowel is significantly lower upon closing the stoma. Long-term complications of ileal conduit diversion are frequent; the most common are stomal or peristomal problems, parastomal hernia, conduit stenosis, and upper tract deterioration.

Radek Chvatal, Dietmar Haas, Cemil Yaman, Peter Oppelt Department of Obstetrics and Gynecology, General Hospital of Linz, Linz, Austria

\section{References}

1. Hong JH, Tsai CS, Lai CH, Chang TC, Wang CC, Chou HH, et al. Recurrence squamous cell carcinoma of cervix after definitive radiotherapy. Int J Radiat Oncol Biol Phys 2004; 60: 249-57. [CrossRef]

2. Cadron I, Van Gorp T, Amant F, Leunen K, Neven P, Vergote I. Chemotherapy for recurrent cervical cancer. Gynecol Oncol 2007; 107: S113-8. [CrossRef]

3. Luis M. Chiva, Fernando Lapuente, Lucía González-Cortijo, Antonio González-Martín, Alejandro Rojo, Juan F. García, Natalia Carballo. Surgical treatment of recurrent cervical cancer. State of the art and new achievements.Gynecologic Oncology. 2008; 110: 60-6. [CrossRef]

4. Fotopoulou C, Neumann U, Kraetschell R, Schefold JC, Weidemann H, Lichtenegger W, Sehouli J, Long-term clinical outcome of pelvic exenteration in patients with advanced gynecological malignancies. Surg. Oncol 2010; 101: 507-12. [CrossRef]

5. Brunschwig A. Complete excision of pelvic viscera for advanced carcinoma. Cancer 1948; 1: 177. [CrossRef]

6. Brunschwig A, Barber HR. Extended pelvic exenteration for advanced cancer of the cervix. Long survivals following added resection of involved small bowel. Cancer 1964; 17: 1267-70. [CrossRef]

7. Magrina JF. Types of pelvic exenterations: a reappraisal. Gynecol Oncol 1990; 37: 363-6. [CrossRef]

8. Bricker EM. Bladder substitution after pelvic evisceration. Surg Clin North Am 1950; 30: 1511-21.

9. Salom EM, Mendez LE, Schey D, Lambrou N, Kassira N, GómezMarn $\mathrm{O}$, et al. Continent ileocolonic urinary reservoir (Miami pouch): the University of Miami experience over 15 years. Am J Obstet Gynecol 2004; 190: 994-1003. [CrossRef] 